\title{
Surgical margin status and its impact on prostate cancer prognosis after radical prostatectomy: a meta-analysis
}

\author{
Lijin Zhang $^{1} \cdot$ Bin Wu ${ }^{1} \cdot$ Zhenlei Zha $^{1} \cdot$ Hu Zhao ${ }^{1} \cdot$ Jun Yuan ${ }^{1} \cdot$ Yuefang Jiang ${ }^{1} \cdot$ Wei Yang $^{1}$
}

Received: 6 March 2018 / Accepted: 8 May 2018 / Published online: 15 May 2018

(c) The Author(s) 2018

\begin{abstract}
Background and purpose Positive surgical margins (PSMs) correlate with adverse outcomes in numerous solid tumours. However, the prognostic value of PSMs in prostate cancer (PCa) patients who underwent radical prostatectomy remains unclear. Herein, we performed a meta-analysis to evaluate the association between PSMs and the prognostic value for biochemical recurrence-free survival (BRFS), cancer-specific survival (CSS), overall survival (OS), cancer-specific mortality (CSM) and overall mortality (OM) in PCa patients.

Materials and methods According to the PRISMA statement, online databases PubMed, EMBASE and Web of Science were searched to identify relevant studies published prior to February 2018. The hazard ratios (HRs) and 95\% confidence intervals (95\% CIs) were calculated to evaluate the relationship between PSMs and PCa.

Results Ultimately, 32 cohort studies that met the eligibility criteria and involved 141,222 patients (51-65,633 per study) were included in this meta-analysis. The results showed that PSMs were significantly predictive of poorer BRFS (HR $=1.35$, 95\% CI $1.28-1.48, p<0.001)$, CSS (HR $=1.49,95 \%$ CI $1.16-1.90, p=0.001)$ and OS $(\mathrm{HR}=1.11,95 \%$ CI $1.02-1.20$, $p=0.014)$. In addition, PSMs were significantly associated with higher risk of CSM (HR $=1.23,95 \% \mathrm{CI} 1.16-1.30, p<0.001)$ and OM (HR $=1.09,95 \%$ CI 1.02-1.16, $p=0.009)$ in patients with PCa.

Conclusions Our study suggests that the presence of a histopathologic PSM is associated with the clinical outcomes BRFS, CSS, OS, CSM and OM in patients with PCa, and PSMs could serve as a poor prognostic factor for patients with PCa.
\end{abstract}

Keywords Prostate cancer $\cdot$ Radical prostatectomy $\cdot$ Positive surgical margin $\cdot$ Prognosis $\cdot$ Meta-analysis

\section{Introduction}

In 2016, prostate cancer (PCa) was the most common newly diagnosed cancer in males, with 1.6 million new cases per year, and 26,730 men died from PCa, which was the third leading cause of cancer death in males [1]. With the wide use of prostate-specific antigen (PSA) screening and

Bin $\mathrm{Wu}$, Zhenlei Zha and $\mathrm{Hu}$ Zhao contributed equally to this work.

Electronic supplementary material The online version of this article (https://doi.org/10.1007/s00345-018-2333-4) contains supplementary material, which is available to authorized users.

Bin $\mathrm{Wu}$

jyrmyywb@163.com

1 Department of Urology, Affiliated Jiang-yin Hospital of the Southeast University Medical College, 163 Shou-shan Road, Jiangyin 214400, Jiangsu, People's Republic of China increased public awareness of $\mathrm{PCa}, 90 \%$ of patients are being diagnosed with localised PCa [2]. Despite effective treatments with curative intent such as radical prostatectomy (RP), up to $30 \%$ of patients will experience biochemical recurrence (BCR), of which $20-30 \%$ will progress to clinical metastasis or death [3]. To date, there have been a number of studies performed to identify histological parameters associated with prognostic outcomes after RP, which might lead to more informative prognostic information in patient monitoring.

A positive surgical margin (PSM) is determined by the stained areas of soft tissue on the RP specimen. The incidence of PSMs is influenced by the presence of extra-prostatic extension, with a rate that ranges from 10 to $48 \%$ [4]. Despite improvements in surgical techniques and standardisation of the RP procedure, PSMs remain an active area of investigation regarding the variability among surgeons and institutions. Several studies have shown that PSMs can predict metastatic progression [5] and/or local recurrence and 
distant metastasis [6, 7], whereas other studies have shown no such relationship [8,9].

Therefore, to further clarify the prognostic value of PSMs in PCa, we performed this meta-analysis based on all published epidemiological studies to evaluate whether the presence of a PSM has a prognostic impact on biochemical recurrence-free survival (BRFS), cancer-specific survival (CSS), overall survival (OS), cancer-specific mortality (CSM) and overall mortality (OM) in patients with $\mathrm{PCa}$.

\section{Materials and methods}

\section{Literature search}

According to the guidelines of the preferred reporting items for systematic reviews and meta-analyses (PRISMA) [10], we searched PubMed, EMBASE and Web of Science from their inception to February 2018. Because the studies included in this meta-analysis have been published, no ethical approval was required. MeSH terms and free words searched for were as follows: 'prostate cancer OR prostate neoplasm', 'radical prostatectomy', 'positive surgical margin', 'survival outcome', 'prognosis' and their combinations.

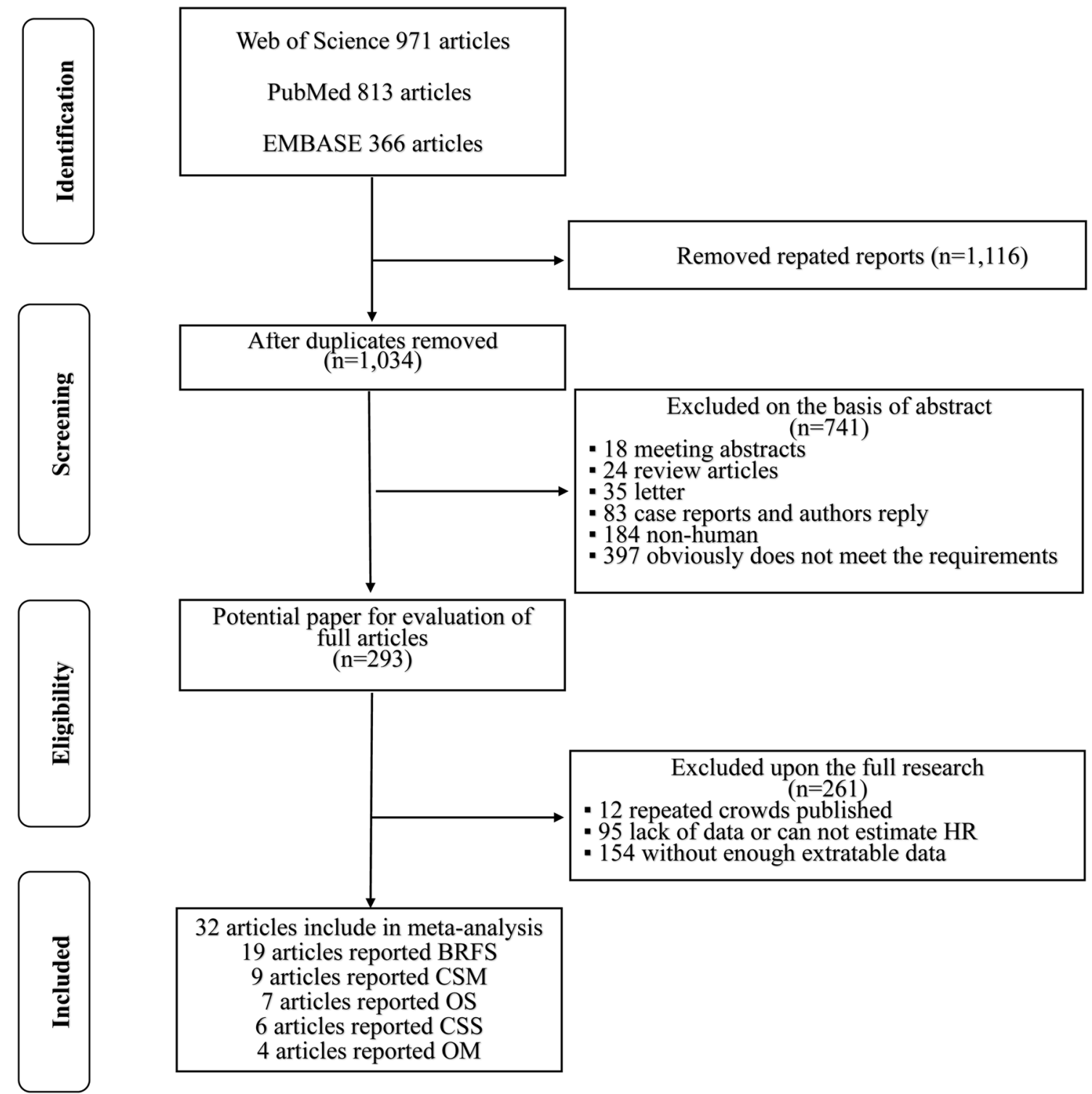

Fig. 1 Flow chart of study selection in this meta-analysis 


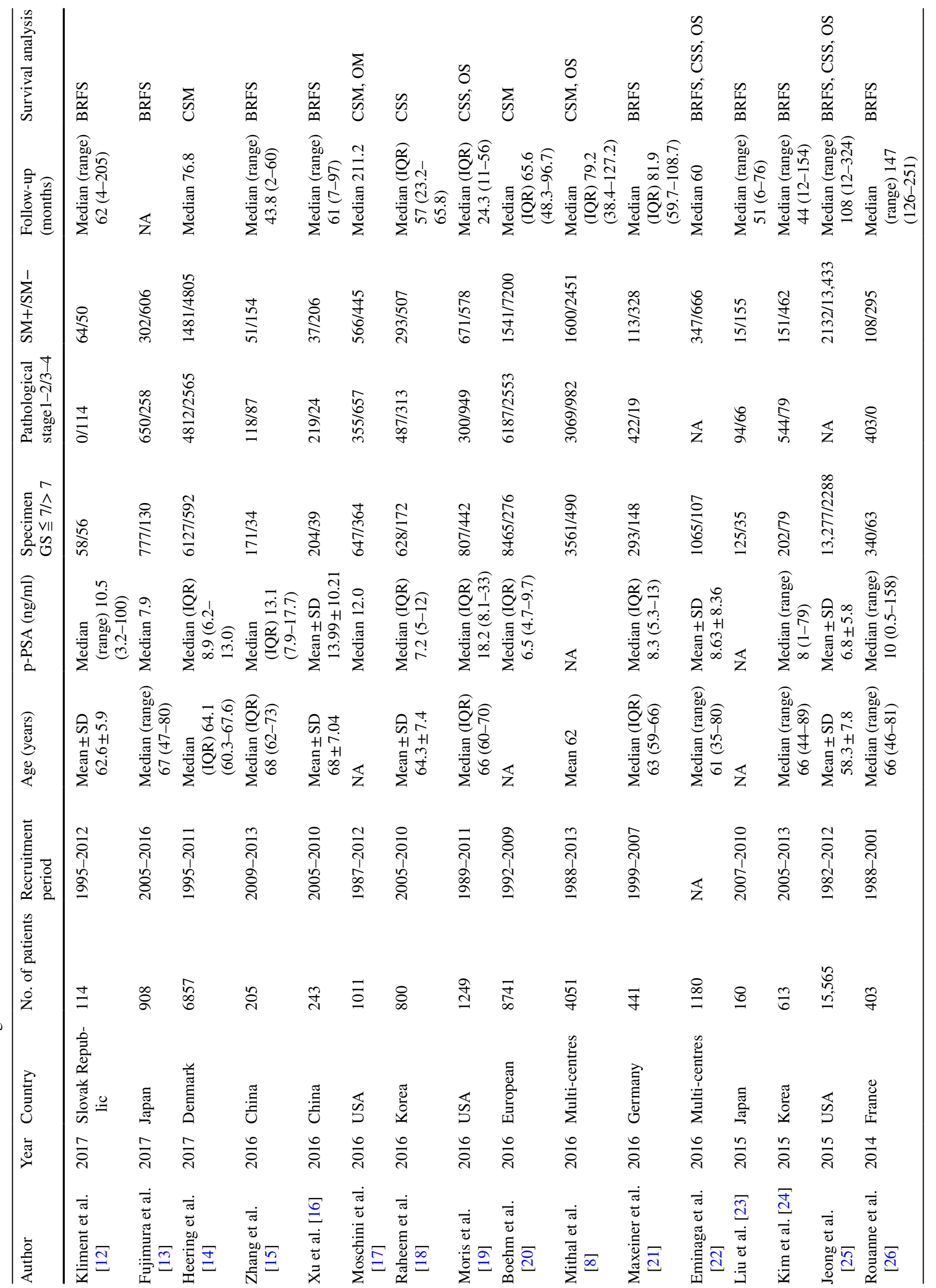




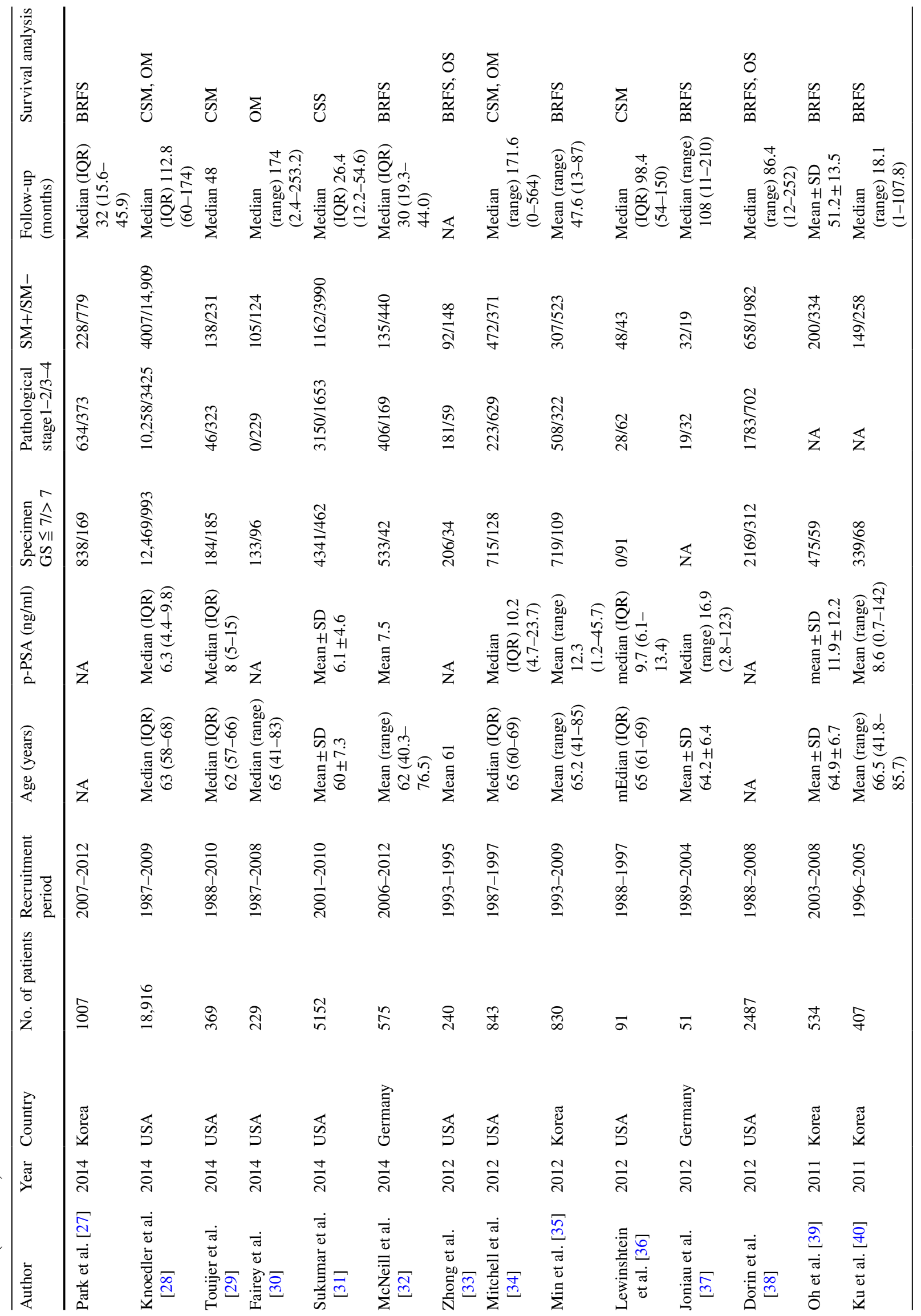


The reference lists of previous relevant reviews were also manually checked to identify all available studies. The language of the publications was restricted to English.

\section{Inclusion and exclusion criteria}

The eligible studies were included only if they met the following criteria: (1) clinical trials that reported patients with PCa; (2) PSM status that was assessed by pathologists; (3) survival outcomes (BRFS, CSS, OS, CSM and $\mathrm{OM})$ of patients with PSMs that were compared with those of patients with negative surgical margins; (4) results that were reported as risk estimate hazard ratios (HRs) with corresponding 95\% confidence intervals (95\% CIs), or sufficient data that was provided to estimate these measures; and (5) the adoption of only the more well-designed, recent and informative publication in this meta-analysis when more than one study analysed the same patient cohort. Accordingly, studies with the following criteria were excluded: (1) reviews, meeting abstracts, letters, case reports, author replies and articles not on humans; (2) studies not related to PCa; (3) studies that did not analyse the presence of a PSM and the clinical features and survival outcomes; and (4) studies lacking sufficient data to acquire HRs and 95\% CIs.

\section{Data extraction and quality assessment}

The following data of the eligible studies were extracted independently by two reviewers (ZLZ and HZ): first author, publication year, country, sample size, recruitment period, age of patients, preoperative PSA, histopathological subtype, follow-up time, and survival end point. All discrepancies in data extraction were resolved by discussion between the two reviewers or consultation with a third reviewer (BW). The quality of the included studies was assessed using the Newcastle-Ottawa scale (NOS) [11] for nonrandomized studies. Each study was assessed by eight methodological items with a score ranging from 0 to 9 . Studies with scores of six or higher were graded as high quality. Only high-quality studies were included for further analysis to assure the quality of this meta-analysis.

\section{Statistical analysis}

Pooled HRs with 95\% CIs were used to evaluate the association of a PSM with PCa prognosis and clinicopathological characteristics. An observed HR $>1$ indicated a poor prognosis for patients with PSMs. Heterogeneity between studies was assessed using the $Q$ and $I^{2}$ statistics. $p<0.10$ or $I^{2}>50 \%$ were used to indicate heterogeneity. A random-effect (RE) model was used when heterogeneity was observed $(p<0.1)$; otherwise, a fixed-effect (FE) model was 
used. To obtain a more precise evaluation of heterogeneity, subgroup analysis was performed for BRFS, CSS, OM and OS based on geographical region, date of publication, mean age, sample size, mean preoperative PSA (p-PSA) concentration, median follow-up and adjuvant radiotherapy (aRT). Sensitivity analysis was performed to test the reliability of the total pooled results by sequential omission of individual studies. In addition, publication bias was assessed using funnel plots and Egger's test. All statistical tests in this meta-analysis were undertaken using Stata 14.0 software (Stata Corporation, College Station, TX). All statistical tests were two-tailed, and $p<0.05$ was considered statistically significant.

\section{Results}

\section{Search results}

Figure 1 shows a flow chart of our selection process. The search strategy yielded 2150 potential studies. According to the exclusion criteria, we excluded 1857 duplicate or not relevant articles on screening of the titles and abstracts. The full text of 293 articles was assessed, and 256 articles were excluded for study groups or insufficient data. Finally, 32 publications [8, 12-42] (19 reporting BRFS, 9 CSM, 7 OS, 6 CSS, 4 OM) published from 2010 to 2017 were included in the meta-analysis.

\section{Study characteristics and quality assessments}

The detailed characteristics of the studies are listed in Table 1. All studies were published between 2010 and 2017, with the mean duration of follow-up varying from 18.1 to 174 months. A total of 141,222 patients (ranging from 51 to 65,633 ) underwent RP for PCa management, of which 31,421 patients were reported to have PSMs. Nine studies $[8,17,19,20,30,32,34,36,37,42]$ reported the use of radiotherapy as an adjuvant therapy after $\mathrm{RP}$, and the proportion of patients who received aRT was $0.2-69 \%$. Of the 32 studies, 11 were conducted in North America, 10 in Asia, 8 in Europe and 3 at international multi-centres. All articles included were published in English. The NOS was applied to assess the quality of the included studies, and the results showed all the studies were of high quality, with an NOS score $\geq 7$ (Supplementary Table S1).

\section{Meta-analysis}

Our meta-analysis demonstrated that a PSM in PCa was associated with poorer BRFS ( RE HR $=1.35,95 \%$ CI
Fig. 2 Forest plots of studies to evaluate the association between PSM and BRFS outcomes in PCa patients

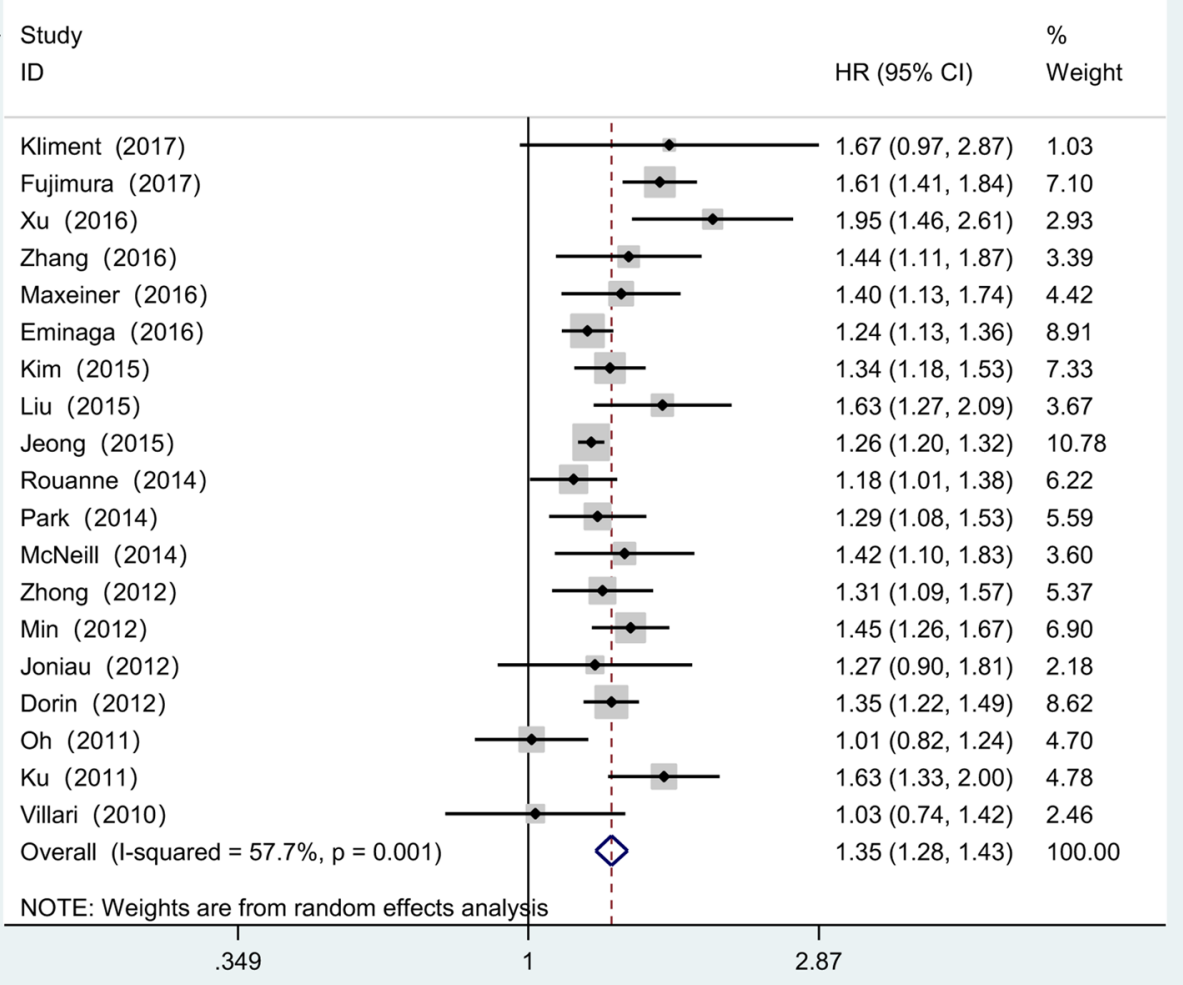


$1.28-1.48, p<0.001, I^{2}=57.7 \%, P_{\text {heterogeneity }}=0.001$, Fig. 2), CSS (RE HR $=1.49,95 \%$ CI $1.16-1.90, p=0.001$, $\boldsymbol{I}^{2}=72.5 \%, P_{\text {heterogeneity }}=0.003$, Fig. $\left.3 \mathrm{a}\right)$ and OS (RE $\mathrm{HR}=1.11,95 \%$ CI 1.02-1.20, $\mathrm{p}=0.014, I^{2}=63.9 \%$, $P_{\text {heterogeneity }}=0.011$, Fig. $3 \mathrm{~b}$ ). In addition, patients with a PSM were found to have an increased risk in terms of CSM $\left(\mathrm{FE} \mathrm{HR}=1.23,95 \%\right.$ CI $1.16-1.30, p<0.001, \boldsymbol{I}^{2}=10.3 \%$, $P_{\text {heterogeneity }}=0.359$, Fig. $\left.3 \mathrm{c}\right)$ and OM (RE HR $=1.09,95 \%$ CI 1.02-1.16, $p=0.009, I^{2}=62.9 \%, P_{\text {heterogeneity }}=0.044$, Fig. 3d). To explore the source of heterogeneity for BRFS, CSS, OS and OM, subgroup analyses stratified by geographical region, date of publication, mean age, sample size, mean p-PSA, median follow-up and aRT (yes/no) were performed. The results of subgroup analyses again suggested a PSM as a prognostic factor despite heterogeneity among some groups (Table 2).

In sensitivity analyses, excluding one study at a time, the pooled HR for BRFS ranged from 1.33 (95\% CI 1.26-1.41) to 1.37 (95\% CI 1.30-1.45). Similarly, the pooled HR for CSS ranged from 1.38 (95\% CI 1.11-1.72) to $1.62(95 \%$ CI 1.28-2.05), the pooled HR for OS ranged from 1.06

A

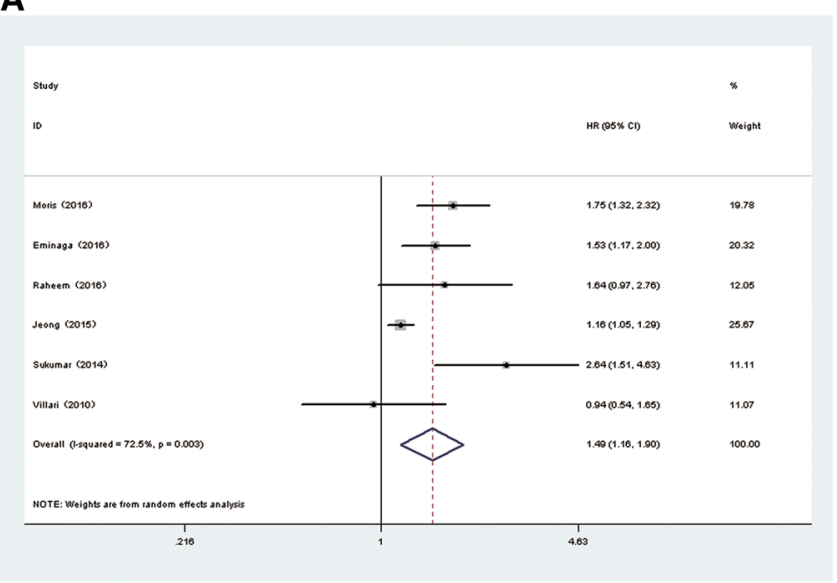

C

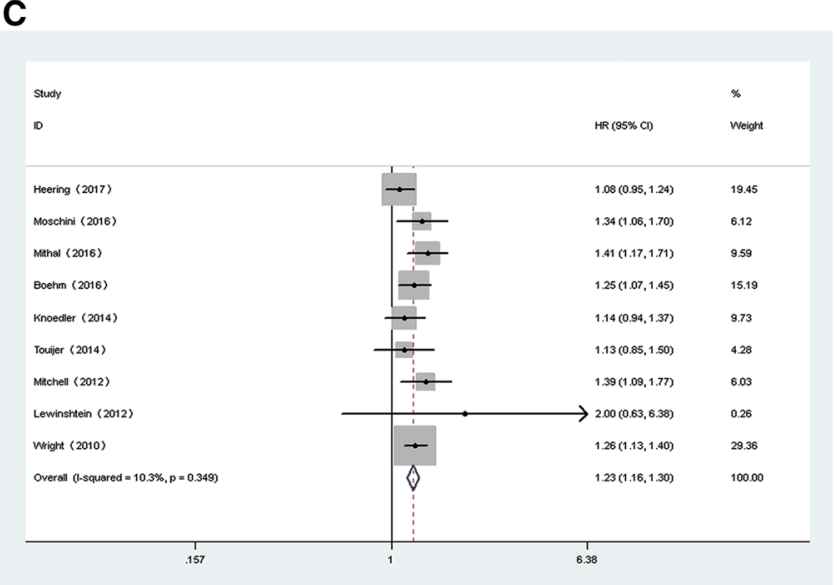

(95\% CI 1.00-1.11) to 1.15 (95\% CI 1.03-1.29), the pooled HR for CSM ranged from 1.21 (95\% CI 1.14-1.29) to 1.27 (95\% CI 1.19-1.35) and the pooled HR for OM ranged from 1.06 (95\% CI 0.98-1.14) to 1.12 (95\% CI 1.08-1.16) (Supplementary Figure S1-5). These results indicated that the findings were reliable and robust. In addition, no statistical evidence of publication bias was found in this meta-analysis, as assessed by Egger's tests for BRFS ( $p$ Egger $=0.108$, Fig. 4a), CSS ( $p$ Egger $=0.146$, Fig. 4b), OS $(p$ Egger $=0.145$, Fig. $4 c)$, CSM $(p$ Egger $=0.353$, Fig. $4 d)$ and OM ( $p$ Egger $=0.457$, Fig. $4 \mathrm{e})$.

\section{Discussion}

Despite diverse multimodality treatment options and extensive studies, PCa remains a major health burden in men, and its diverse clinical outcomes regarding progression is a challenge to be addressed. As a result, various factors, including pathologic features and novel molecular biomarkers, are currently regarded as being useful for predicting

B

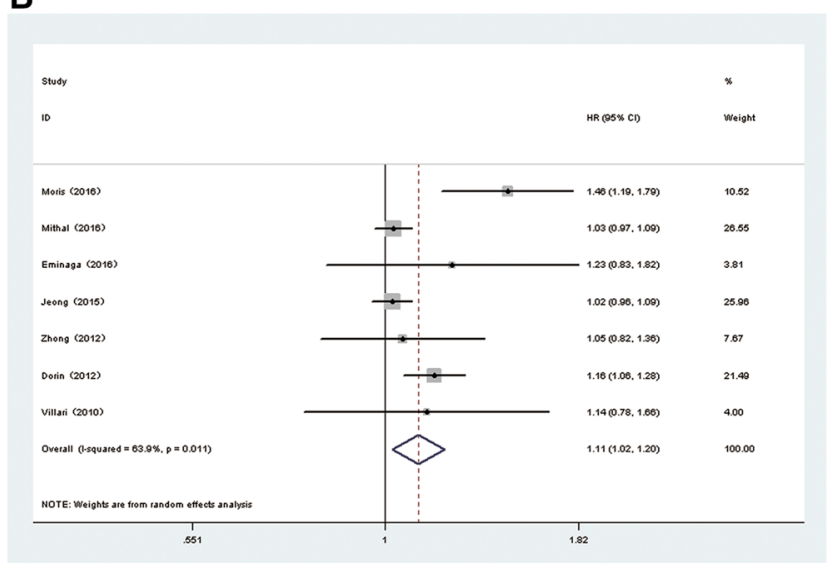

D

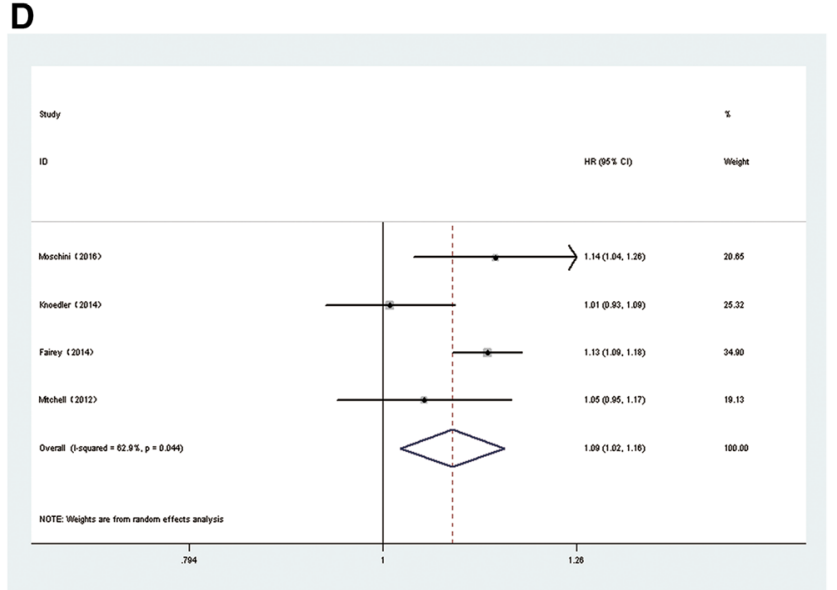

Fig. 3 Forest plots of studies to evaluate the association between PSM and prognostic outcomes in PCa patients: a CSS, b OS, c CSM, d OM 
Table 2 Summary and subgroup analysis for the eligible studies $\begin{array}{lllll}\text { Analysis specification } & \text { No. of studies } & \text { Study heteroge- } & \text { Effects model } & \text { Pooled HR (95\% CI) }\end{array} \quad P$ value neity

$\overline{I^{2}(\%) \quad P_{\text {heterogeneit }}}$

\section{BRFS}

Overall

19

Geographical region

Asia 9

Other regions $\quad 10$

Date of publication

$$
\geq 2015
$$

$<2015$

9
10

Mean age (years)

$\geq 65$

$<65$

Sample size (cases)

$\geq 800$

$<800$

Mean p-PSA (ng/ml)

$\geq 10$

$<10$

10

9

7

Median follow-up

$\geq 65$ months

$<65$ months

6

Adjuvant radiotherapy

Yes

No

CSS

Overall

Geographical region

Other regions

Date of publication

$\geq 2015$

$<2015$

Mean age (years)

$\geq 65$

$<65$

Mean p-PSA (ng/ml)

$\geq 10$

$<10$

Median follow-up

$\geq 65$ months

$<65$ months

$\mathrm{OM}$

Overall

Date of publication

$<2015$

Mean age (years)

$\geq 65$

Sample size (cases)

$\geq 800$

Mean p-PSA (ng/ml)

$\geq 10$

\begin{tabular}{|c|c|c|c|c|}
\hline 57.7 & 0.001 & Random & $1.35(1.28,1.43)$ & $<0.001$ \\
\hline 65.6 & 0.003 & Random & $1.44(1.30,1.61)$ & $<0.001$ \\
\hline 0 & 0.634 & Fixed & $1.27(1.22,1.31)$ & $<0.001$ \\
\hline 68.3 & 0.001 & Random & $1.42(1.29,1.55)$ & $<0.001$ \\
\hline 48 & 0.044 & Random & $1.30(1.20,1.41)$ & $<0.001$ \\
\hline 75.7 & $<0.001$ & Random & $1.43(1.28,1.60)$ & $<0.001$ \\
\hline 19.4 & 0.282 & Fixed & $1.26(1.16,1.37)$ & $<0.001$ \\
\hline 65.9 & 0.007 & Random & $1.33(1.23,1.43)$ & $<0.001$ \\
\hline 53 & 0.016 & Random & $1.38(1.26,1.52)$ & $<0.001$ \\
\hline 65.6 & 0.005 & Random & $1.32(1.13,1.53)$ & $<0.001$ \\
\hline 68.1 & 0.005 & Random & $1.38(1.27,1.50)$ & $<0.001$ \\
\hline 0 & 0.421 & Fixed & $1.27(1.22,1.32)$ & $<0.001$ \\
\hline 59.5 & 0.006 & Random & $1.39(1.27,1.53)$ & $<0.001$ \\
\hline 0 & 0.628 & Fixed & $1.37(1.11,1.68)$ & 0.003 \\
\hline 64 & $<0.001$ & Random & $1.35(1.27,1.44)$ & $<0.001$ \\
\hline 72.5 & 0.003 & Random & $1.49(1.16,1.90)$ & 0.001 \\
\hline 76.8 & 0.002 & Random & $1.47(1.12,1.92)$ & 0.005 \\
\hline 71.5 & 0.015 & Random & $1.45(1.14,1.84)$ & 0.003 \\
\hline 84.6 & 0.011 & Random & $1.58(0.74,4.34)$ & 0.377 \\
\hline 73.1 & 0.054 & Random & $1.35(0.74,2.45)$ & 0.328 \\
\hline 74.9 & 0.007 & Random & $1.54(1.13,2.09)$ & 0.006 \\
\hline 73.1 & 0.054 & Random & $1.35(0.74,2.45)$ & 0.328 \\
\hline 74.9 & 0.007 & Random & $1.54(1.13,2.09)$ & 0.006 \\
\hline 0 & 0.472 & Fixed & $1.15(1.04,1.28)$ & 0.006 \\
\hline 1.8 & 0.383 & Fixed & $1.71(1.43,2.04)$ & $<0.001$ \\
\hline 62.9 & 0.044 & Random & $1.09(1.02,1.16)$ & 0.009 \\
\hline 73.3 & 0.024 & Random & $1.07(0.99,1.18)$ & 0.002 \\
\hline 41.6 & 0.191 & Fixed & $1.11(1.04,1.79)$ & 0.004 \\
\hline 49.5 & 0.138 & Fixed & $1.06(0.99,1.14)$ & 0.115 \\
\hline 26. & 0.244 & Fixed & $1.10(1.01,1.19)$ & 0.026 \\
\hline
\end{tabular}


Table 2 (continued)

\begin{tabular}{|c|c|c|c|c|c|c|}
\hline \multirow[t]{2}{*}{ Analysis specification } & \multirow[t]{2}{*}{ No. of studies } & \multicolumn{2}{|c|}{$\begin{array}{l}\text { Study heteroge- } \\
\text { neity }\end{array}$} & \multirow[t]{2}{*}{ Effects model } & \multirow[t]{2}{*}{ Pooled HR (95\% CI) } & \multirow[t]{2}{*}{$P$ value } \\
\hline & & $I^{2}(\%)$ & $P_{\text {heterogeneit }}$ & & & \\
\hline \multicolumn{7}{|l|}{ Adjuvant radiotherapy } \\
\hline Yes & 3 & 0 & 0.396 & Fixed & $1.12(1.08,1.16)$ & $<0.001$ \\
\hline \multicolumn{7}{|l|}{ OS } \\
\hline Overall & 7 & 63.9 & 0.011 & Random & $1.11(1.02,1.20)$ & 0.014 \\
\hline \multicolumn{7}{|l|}{ Date of publication } \\
\hline$\geq 2015$ & 4 & 75 & 0.007 & Random & $1.10(0.99,1.23)$ & 0.082 \\
\hline$<2015$ & 3 & 0 & 0.772 & Fixed & $1.15(1.05,1.25)$ & 0.002 \\
\hline \multicolumn{7}{|l|}{ Mean age (years) } \\
\hline$\geq 65$ & 2 & 23.8 & 0.252 & Fixed & $1.36(1.09,1.70)$ & 0.007 \\
\hline$<65$ & 4 & 0 & 0.827 & Fixed & $1.03(0.99,1.07)$ & 0.212 \\
\hline \multicolumn{7}{|l|}{ Sample size (cases) } \\
\hline$\geq 800$ & 6 & 69.9 & 0.005 & Random & $1.11(1.02,1.22)$ & 0.016 \\
\hline \multicolumn{7}{|l|}{ Mean p-PSA (ng/ml) } \\
\hline$<10$ & 3 & 0 & 0.572 & Fixed & $1.03(0.97,1.09)$ & 0.358 \\
\hline \multicolumn{7}{|l|}{ Median follow-up } \\
\hline$\geq 65$ months & 4 & 50.4 & 0.109 & Fixed & $1.06(0.99,1.13)$ & 0.074 \\
\hline$<65$ months & 2 & 0 & 0.444 & Fixed & $1.41(1.18,1.69)$ & $<0.001$ \\
\hline
\end{tabular}

the prognostic outcomes of RP. Nevertheless, PCa has been shown to be characterised by unique biological features and heterogeneous genetic backgrounds, indicating the limitations for predicting postoperative prognostic outcomes in patients with localised PCa [43].

$\mathrm{RP}$ with pelvic lymph node dissection is the standard of care for localised PCa, with the goals of providing good oncologic and functional outcomes, especially in patients with good life expectancy. However, a proportion of patients inevitably demonstrate adverse pathologic features such as PSMs, seminal vesicle invasion [44], lymph node metastasis [45] and perineural invasion [46]. The reported incidence of PSMs, notwithstanding its significant decrease with RP because of the advances in surgical techniques, signifies locally adverse pathology, and PSMs remain an ominous prognostic factor [47, 48]; moreover, the management of patients with PSMs remains challenging. Furthermore, the impact of PSMs on control of PCa has been controversial. For example, in an analysis of the pathological reports of 65,633 specimens from RPs, Wright et al. demonstrated the independent role of a PSM in PCa [26]. Subsequently, Alkhateeb et al. [49] reported that a PSM was an independent predictor of BRFS in patients with intermediate- and high-risk PCa. However, Mithal et al. [8] reported that a PSM was significantly associated with all adverse outcomes in unadjusted models, although PSMs were only associated with increased risk of BCR $(\mathrm{HR}=1.98, p<0.001)$ and not with castration-resistant disease, metastases, or CSM $(\mathrm{HR} \leq 1.29, p>0.18)$ after adjusting for demographic and pathological characteristics.
Patients with BCR following RP have been shown to be at increased risk for subsequent metastases and death. However, BCR represents an early event in the natural history of PCa with heterogeneous outcomes, and BCR does not systematically translate into clinical progression [42]. Although previous studies have found that PSMs are associated with an increased risk of BCR, their association with more clinically robust endpoints is still controversial [50]. The prognostic heterogeneity may often have been incompletely characterised due to limitations in sample size, and only a large study with enough events can evaluate whether a PSM is an independent predictor of clinical outcome. In this meta-analysis, we synthesised 32 studies with a large sample of 75,589 patients, including 31,421 PSM patients (22.2\%), to explore the relationship between PSMs and oncologic outcomes in localised PCa.

To the best of our knowledge, the present study was the first to systematically evaluate the prognostic value of PSM in patients with PCa, and the data showed that a PSM was a predictor for BRFS $(\mathrm{HR}=1.35, p<0.001)$, CSS $(\mathrm{HR}=1.49$, $p=0.001)$, OS $(\mathrm{HR}=1.11, p=0.014), \mathrm{CSM}(\mathrm{HR}=1.23$, $p<0.001)$ and $\mathrm{OM}(\mathrm{HR}=1.09, p=0.009)$. The findings were consistently independent of geographical region, publication year, age, sample size, p-PSA, follow-up duration and aRT (yes/no). Sensitivity analyses indicated that the findings were reliable and robust. In addition, there was no evidence of significant publication bias in these analyses according to Begg's tests. Although there was no evidence of heterogeneity in terms of CSM, significant heterogeneity was detected in the analysis of the BRFS, CSS, OS and 

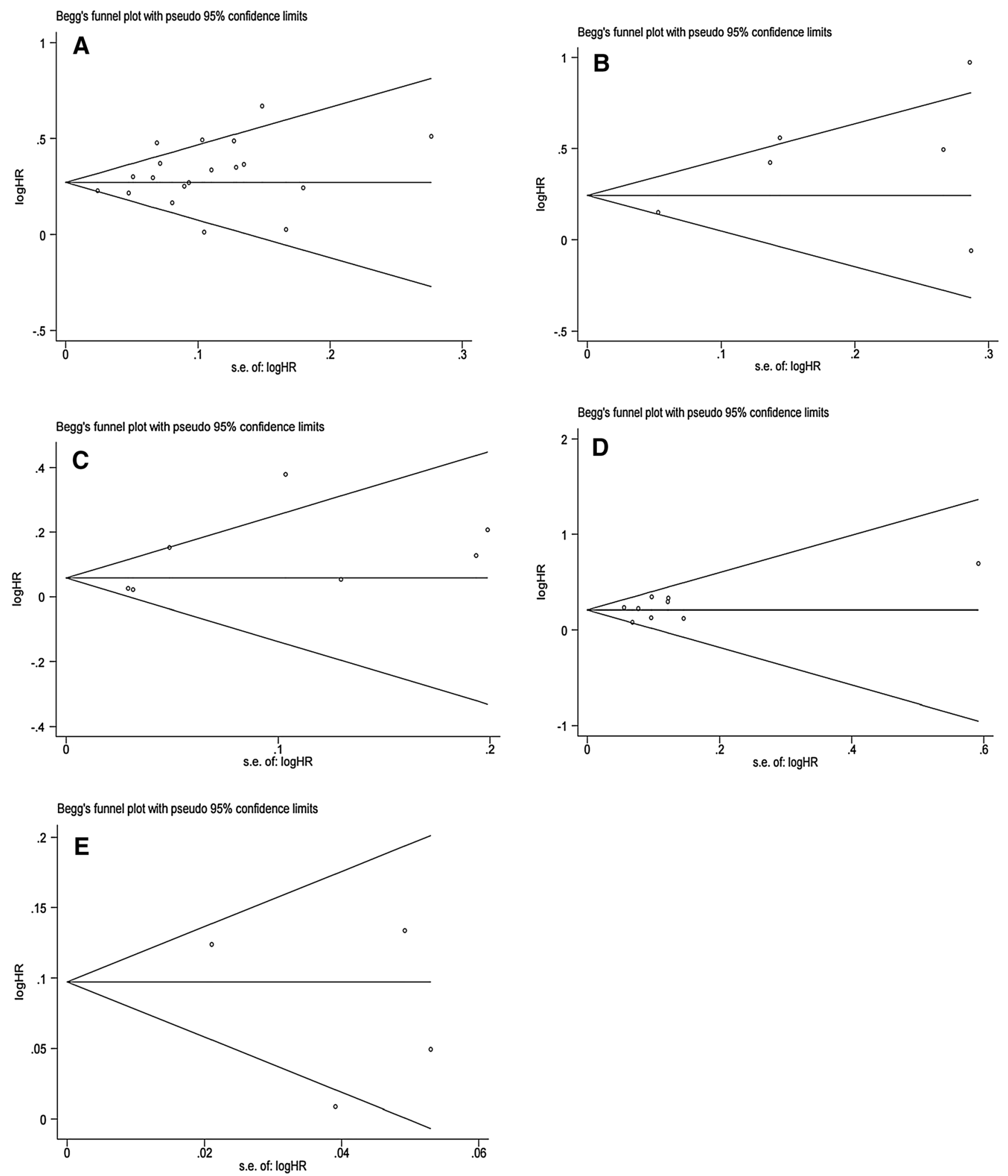

Fig. 4 Funnel plots for evaluating publication bias of the hazard ratios (HRs): a BRFS, b CSS, c OS, d CSM, e OM

OM models. To further explore the source of heterogeneity, subgroup analyses were conducted. Our data showed that the significant variations were reduced within some items.
Although we used a systematic method to perform the present study, the following limitations also should be taken into account. First, the applied methods for detecting PSMs in the pathologic specimen were varied 
in the included studies, which may cause heterogeneity among the studies. Second, substantial heterogeneity was observed in the meta-analysis; although we chose the RE model according to heterogeneity, it still existed in our studies. The heterogeneity was probably caused by differences in factors such as the patients' characteristics and different durations of follow-up. Third, we only included published studies written in English, and grey literature was not included, which may cause selection bias. Fourth, all the included studies were retrospective cohort studies, and data extracted from those studies may have led to inherent potential bias.

Nevertheless, the present study has several key strengths. First, the meta-analysis included 32 studies with a large sample size to detect more stable associations between PSMs and clinical outcomes of PCa patients. Second, with the strict inclusion and exclusion criteria, we extracted available data from relevant studies. Furthermore, the results were found to be reliable and robust through subgroup and sensitivity analyses. Therefore, PSM determination, with excellent accessibility and low costs, warrants wider application in patients with PCa for risk stratification and decisionmaking of individualised treatment.

In conclusion, the results of this meta-analysis demonstrated that the finding of PSMs by histopathology is closely associated with poor survival in patients with PCa. Due to limitations in this study, large-scale, multicentre prospective studies with standardised methods and long-term follow-up are needed to verify our results.

\section{Availability of materials and data}

All data generated or analysed during this study are included in this published article (and its supplementary information files).

Author contribution $\mathrm{LJZ}$ and BW designed the research; ZLZ, HZ and JY performed the literature search; YFJ and WY analysed the data and interpreted the results; LJZ wrote the paper; all authors approved the final manuscript.

\section{Compliance with ethical standards}

Conflict of interest We declare that there are no potential competing interests in this research.

Informed consent For this type of study, formal consent is not required.

Human and animal rights This article does not contain any studies with human participants or animals performed by any of the authors.

Open Access This article is distributed under the terms of the Creative Commons Attribution 4.0 International License (http://creativecommons.org/licenses/by/4.0/), which permits unrestricted use, distribution, and reproduction in any medium, provided you give appropriate credit to the original author(s) and the source, provide a link to the Creative Commons license, and indicate if changes were made.

\section{References}

1. Siegel RL, Miller KD, Jemal A (2017) Cancer statistics, 2017. CA Cancer J Clin 67(1):7-30. https://doi.org/10.3322/caac.21387

2. Edwards BK, Noone AM, Mariotto AB, Simard EP, Boscoe FP, Henley SJ, Jemal A, Cho H, Anderson RN, Kohler BA, Eheman CR, Ward EM (2014) Annual report to the nation on the status of cancer, 1975-2010, featuring prevalence of comorbidity and impact on survival among persons with lung, colorectal, breast, or prostate cancer. Cancer 120(9):1290-1314. https://doi. org/10.1002/cncr.28509

3. Loeb S, Feng Z, Ross A, Trock BJ, Humphreys EB, Walsh PC (2011) Can we stop prostate specific antigen testing 10 years after radical prostatectomy? J Urol 186(2):500-505. https://doi. org/10.1016/j.juro.2011.03.116

4. Eastham JA, Kattan MW, Riedel E, Begg CB, Wheeler TM, Gerigk C, Gonen M, Reuter V, Scardino PT (2003) Variations among individual surgeons in the rate of positive surgical margins in radical prostatectomy specimens. J Urol 170(6 Pt 1):2292-2295. https://doi.org/10.1097/01.ju.0000091100.83725.51

5. Vis AN, Schroder FH, van der Kwast TH (2006) The actual value of the surgical margin status as a predictor of disease progression in men with early prostate cancer. Eur Urol 50(2):258-265. https ://doi.org/10.1016/j.eururo.2005.11.030

6. Swindle P, Eastham JA, Ohori M, Kattan MW, Wheeler T, Maru N, Slawin K, Scardino PT (2008) Do margins matter? The prognostic significance of positive surgical margins in radical prostatectomy specimens. J Urol 179(5 Suppl):S47-S51. https://doi. org/10.1016/j.juro.2008.03.137

7. Pfitzenmaier J, Pahernik S, Tremmel T, Haferkamp A, Buse S, Hohenfellner M (2008) Positive surgical margins after radical prostatectomy: do they have an impact on biochemical or clinical progression? BJU Int 102(10):1413-1418. https://doi. org/10.1111/j.1464-410X.2008.07791.X

8. Mithal P, Howard LE, Aronson WJ, Terris MK, Cooperberg MR, Kane CJ, Amling C, Freedland SJ (2016) Positive surgical margins in radical prostatectomy patients do not predict long-term oncological outcomes: results from the Shared Equal Access Regional Cancer Hospital (SEARCH) cohort. BJU Int 117(2):244-248. https://doi.org/10.1111/bju.13181

9. Hull GW, Rabbani F, Abbas F, Wheeler TM, Kattan MW, Scardino PT (2002) Cancer control with radical prostatectomy alone in 1000 consecutive patients. J Urol 167(2 Pt 1):528-534

10. Liberati A, Altman DG, Tetzlaff J, Mulrow C, Gotzsche PC, Ioannidis JP, Clarke M, Devereaux PJ, Kleijnen J, Moher D (2009) The PRISMA statement for reporting systematic reviews and meta-analyses of studies that evaluate health care interventions: explanation and elaboration. J Clin Epidemiol 62(10):e134. https://doi.org/10.1016/j.jclinepi.2009.06.006

11. Stang A (2010) Critical evaluation of the Newcastle-Ottawa scale for the assessment of the quality of nonrandomized studies in meta-analyses. Eur J Epidemiol 25(9):603-605. https://doi. org/10.1007/s10654-010-9491-Z

12. Kliment J Jr, Elias B, Baluchova K, Kliment J Sr (2017) The long-term outcomes of radical prostatectomy for very high-risk prostate cancer pT3b-T4 N0-1 on definitive histopathology. Cent Euro J Urol 70(1):13-19. https://doi.org/10.5173/ceju.2017.897

13. Fujimura T, Fukuhara H, Taguchi S, Yamada Y, Sugihara T, Nakagawa T, Niimi A, Kume H, Igawa Y, Homma Y (2017) Robot-assisted radical prostatectomy significantly reduced 
biochemical recurrence compared to retro pubic radical prostatectomy. BMC Cancer 17(1):454. https://doi.org/10.1186/s1288 5-017-3439-6

14. Heering M, Berg KD, Brasso K, Iversen P, Roder MA (2017) Radical prostatectomy in Denmark: survival analysis and temporal trends in clinicopathological parameters with up to 20 years of follow-up. Surg Oncol 26(1):21-27. https://doi.org/10.1016/j. suronc.2016.12.002

15. Zhang YD, Wang J, Wu CJ, Bao ML, Li H, Wang XN, Tao J, Shi HB (2016) An imaging-based approach predicts clinical outcomes in prostate cancer through a novel support vector machine classification. Oncotarget 7(47):78140-78151. https://doi.org/10.18632/ oncotarget.11293

16. Xu N, Chen HJ, Chen SH, Xue XY, Chen H, Zheng QS, Wei Y, Li XD, Huang JB, Cai H, Sun XL (2016) Reduced Connexin 43 expression is associated with tumor malignant behaviors and biochemical recurrence-free survival of prostate cancer. Oncotarget 7(41):67476-67484. https://doi.org/10.18632/oncotarget.11231

17. Moschini M, Sharma V, Zattoni F, Boorjian SA, Frank I, Gettman MT, Thompson RH, Tollefson MK, Kwon ED, Karnes RJ (2016) Risk stratification of $\mathrm{pN}+$ prostate cancer after radical prostatectomy from a large single institutional series with long-term followup. J Urol 195(6):1773-1778. https://doi.org/10.1016/j. juro.2015.12.074

18. Abdel Raheem A, Kim DK, Santok GD, Alabdulaali I, Chung BH, Choi YD, Rha KH (2016) Stratified analysis of 800 Asian patients after robot-assisted radical prostatectomy with a median 64 months of follow up. Int J Urol 23(9):765-774. https://doi. org/10.1111/iju.13151

19. Moris L, Van den Broeck T, Tosco L, Van Baelen A, Gontero P, Karnes RJ, Everaerts W, Albersen M, Bastian PJ, Chlosta P, Claessens F, Chun FK, Graefen M, Gratzke C, Kneitz B, Marchioro G, Salas RS, Tombal B, Van Der Poel H, Walz JC, De Meerleer G, Bossi A, Haustermans K, Montorsi F, Van Poppel H, Spahn M, Briganti A, Joniau S (2016) Impact of lymph node burden on survival of high-risk prostate cancer patients following radical prostatectomy and pelvic lymph node dissection. Front Surg 3:65. https://doi.org/10.3389/fsurg.2016.00065

20. Boehm K, Larcher A, Tian Z, Mandel P, Schiffmann J, Karakiewicz PI, Graefen M, Huland H, Tilki D (2016) Low other cause mortality rates reflect good patient selection in patients with prostate cancer treated with radical prostatectomy. J Urol 196(1):8288. https://doi.org/10.1016/j.juro.2016.01.122

21. Maxeiner A, Magheli A, Johrens K, Kilic E, Braun TL, Kempkensteffen C, Hinz S, Stephan C, Miller K, Busch J (2016) Significant reduction in positive surgical margin rate after laparoscopic radical prostatectomy by application of the modified surgical margin recommendations of the 2009 international society of urological pathology consensus. BJU Int 118(5):750-757. https://doi. org/10.1111/bju.13451

22. Eminaga O, Wei W, Hawley SJ, Auman H, Newcomb LF, Simko J, Hurtado-Coll A, Troyer DA, Carroll PR, Gleave ME, Lin DW, Nelson PS, Thompson IM, True LD, McKenney JK, Feng Z, Fazli L, Brooks JD (2016) MUC1 expression by immunohistochemistry is associated with adverse pathologic features in prostate cancer: a multi-institutional study. PLoS One 11(11):e0165236. https:// doi.org/10.1371/journal.pone.0165236

23. Liu B, Miyake H, Nishikawa M, Tei H, Fujisawa M (2015) Expression profile of autophagy-related markers in localized prostate cancer: correlation with biochemical recurrence after radical prostatectomy. Urology 85(6):1424-1430. https://doi. org/10.1016/j.urology.2015.03.006

24. Kim SH, Kim SH, Joung JY, Lee GK, Hong EK, Kang KM, Yu A, Nam BH, Chung J, Seo HK, Park WS, Lee KH (2015) Overexpression of ERG and wild-type PTEN are associated with favorable clinical prognosis and low biochemical recurrence in prostate cancer. PLoS One 10(4):e0122498. https://doi.org/10.1371/journ al.pone. 0122498

25. Jeong BC, Chalfin HJ, Lee SB, Feng Z, Epstein JI, Trock BJ, Partin AW, Humphreys E, Walsh PC, Han M (2015) The relationship between the extent of extraprostatic extension and survival following radical prostatectomy. Eur Urol 67(2):342-346. https ://doi.org/10.1016/j.eururo.2014.06.015

26. Rouanne M, Rode J, Campeggi A, Allory Y, Vordos D, Hoznek A, Abbou CC, De La Taille A, Salomon L (2014) Long-term impact of positive surgical margins on biochemical recurrence after radical prostatectomy: ten years of follow-up. Scand J Urol 48(2):131-137. https://doi.org/10.3109/21681805.2013.813067

27. Park J, Yoo DS, Song C, Park S, Park S, Kim SC, Cho Y, Ahn H (2014) Comparison of oncological outcomes between retropubic radical prostatectomy and robot-assisted radical prostatectomy: an analysis stratified by surgical experience. World J Urol 32(1):193-199. https://doi.org/10.1007/s00345-013-1168-2

28. Knoedler JJ, Karnes RJ, Thompson RH, Rangel LJ, Bergstralh EJ, Boorjian SA (2014) The association of tumor volume with mortality following radical prostatectomy. Prostate Cancer Prostatic Dis 17(2):144-148. https://doi.org/10.1038/pcan.2013.61

29. Touijer KA, Mazzola CR, Sjoberg DD, Scardino PT, Eastham JA (2014) Long-term outcomes of patients with lymph node metastasis treated with radical prostatectomy without adjuvant androgen-deprivation therapy. Eur Urol 65(1):20-25. https:// doi.org/10.1016/j.eururo.2013.03.053

30. Fairey AS, Daneshmand S, Skinner EC, Schuckman A, Cai J, Lieskovsky G (2014) Long-term cancer control after radical prostatectomy and bilateral pelvic lymph node dissection for pT3bN0M0 prostate cancer in the prostate-specific antigen era. Urol Oncol 32(2):85-91. https://doi.org/10.1016/j.urolo nc.2013.03.005

31. Sukumar S, Rogers CG, Trinh QD, Sammon J, Sood A, Stricker H, Peabody JO, Menon M, Diaz-Insua M (2014) Oncological outcomes after robot-assisted radical prostatectomy: long-term follow-up in 4803 patients. BJU Int 114(6):824-831. https://doi. org/10.1111/bju.12404

32. McNeill SA, Good DW, Stewart GD, Stolzenburg JU (2014) Five-year oncological outcomes of endoscopic extraperitoneal radical prostatectomy (EERPE) for prostate cancer: results from a medium-volume UK centre. BJU Int 113(3):449-457. https:// doi.org/10.1111/bju.12260

33. Zhong WD, Liang YX, Lin SX, Li L, He HC, Bi XC, Han ZD, Dai QS, Ye YK, Chen QB, Wang YS, Zeng GH, Zhu G, Zhang Z, Chen ZN, Wu CL (2012) Expression of CD147 is associated with prostate cancer progression. Int J Cancer 130(2):300-308. https://doi.org/10.1002/ijc.25982

34. Mitchell CR, Boorjian SA, Umbreit EC, Rangel LJ, Carlson RE, Karnes RJ (2012) 20-Year survival after radical prostatectomy as initial treatment for cT3 prostate cancer. BJU Int 110(11):1709-1713. https://doi.org/10.1111/j.1464410X.2012.11372.X

35. Min SH, Park YH, Lee SB, Ku JH, Kwak C, Kim HH (2012) Impact of prostate size on pathologic outcomes and prognosis after radical prostatectomy. Korean J Urol 53(7):463-466. https ://doi.org/10.4111/kju.2012.53.7.463

36. Lewinshtein D, Teng B, Valencia A, Gibbons R, Porter CR (2012) The long-term outcomes after radical prostatectomy of patients with pathologic Gleason 8-10 disease. Adv Urol 2012:428098. https://doi.org/10.1155/2012/428098

37. Joniau S, Hsu CY, Gontero P, Spahn M, Van Poppel H (2012) Radical prostatectomy in very high-risk localized prostate cancer: long-term outcomes and outcome predictors. Scand J Urol Nephrol 46(3):164-171. https://doi.org/10.3109/00365599.2011.63795 6 
38. Dorin RP, Daneshmand S, Lassoff MA, Cai J, Skinner DG, Lieskovsky G (2012) Long-term outcomes of open radical retropubic prostatectomy for clinically localized prostate cancer in the prostate-specific antigen era. Urology 79(3):626-631. https://doi. org/10.1016/j.urology.2011.09.051

39. Oh JJ, Lee SC, Jeong CW, Yoon CY, Jeong SJ, Hong SK, Byun SS, Rho YK, Choe G, Lee SE (2011) The prognostic significance of percentage of tumour involvement according to disease risk group in men treated with radical prostatectomy. Asian J Androl 13(6):828-832. https://doi.org/10.1038/aja.2011.111

40. Ku JH, Moon KC, Cho SY, Kwak C, Kim HH (2011) Serum prostate-specific antigen value adjusted for non-cancerous prostate tissue volume in patients undergoing radical prostatectomy: a new predictor of biochemical recurrence in localized or locally advanced prostate cancer. Asian J Androl 13(2):248-253. https:// doi.org/10.1038/aja.2010.152

41. Villari D, Nesi G, Della Melina A, Palli D, Ceroti M, Castigli M, Filocamo MT, Li Marzi V, Nicita G (2010) Radical retropubic prostatectomy for prostate cancer with microscopic bladder neck involvement: survival and prognostic implications. BJU Int 105(7):946-950. https://doi.org/10.1111/j.1464-410X.2009.08914 .X

42. Wright JL, Dalkin BL, True LD, Ellis WJ, Stanford JL, Lange PH, Lin DW (2010) Positive surgical margins at radical prostatectomy predict prostate cancer specific mortality. J Urol 183(6):22132218. https://doi.org/10.1016/j.juro.2010.02.017

43. Mackinnon AC, Yan BC, Joseph LJ, Al-Ahmadie HA (2009) Molecular biology underlying the clinical heterogeneity of prostate cancer: an update. Arch Pathol Lab Med 133(7):1033-1040. https://doi.org/10.1043/1543-2165-133.7.1033

44. Lee T, Hoogenes J, Wright I, Matsumoto ED, Shayegan B (2017) Utility of preoperative 3 Tesla pelvic phased-array multiparametric magnetic resonance imaging in prediction of extracapsular extension and seminal vesicle invasion of prostate cancer and its impact on surgical margin status: experience at a Canadian academic tertiary care centre. Can Urol Assoc J 11(5):e174-e178. https://doi.org/10.5489/cuaj.4211

45. Luchini C, Fleischmann A, Boormans JL, Fassan M (2017) Extranodal extension of lymph node metastasis influences recurrence in prostate cancer: a systematic review and meta-analysis. Sci Rep 7(1):2374. https://doi.org/10.1038/s41598-017-02577-4

46. Dell'Atti L (2016) Prognostic significance of perineural invasion in patients who underwent radical prostatectomy for localized prostate cancer. J BUON 21(5):1219-1223

47. Stephenson AJ, Kattan MW, Eastham JA, Bianco FJ Jr, Yossepowitch O, Vickers AJ, Klein EA, Wood DP, Scardino PT (2009) Prostate cancer-specific mortality after radical prostatectomy for patients treated in the prostate-specific antigen era. J Clin Oncol 27(26):4300-4305. https://doi.org/10.1200/jco.2008.18.2501

48. Fontenot PA, Mansour AM (2013) Reporting positive surgical margins after radical prostatectomy: time for standardization. BJU Int 111(8):E290-E299. https://doi.org/10.1111/j.1464410X.2012.11640.x

49. Alkhateeb S, Alibhai S, Fleshner N, Finelli A, Jewett M, Zlotta A, Nesbitt M, Lockwood G, Trachtenberg J (2010) Impact of positive surgical margins after radical prostatectomy differs by disease risk group. J Urol 183(1):145-150. https://doi.org/10.1016/j. juro.2009.08.132

50. Yossepowitch O, Briganti A, Eastham JA, Epstein J, Graefen M, Montironi R, Touijer K (2014) Positive surgical margins after radical prostatectomy: a systematic review and contemporary update. Eur Urol 65(2):303-313. https://doi.org/10.1016/j.eurur o.2013.07.039 